\title{
The Incidence of Rotavirus and Adenovirus Infections among Children with Diarrhea in Sulaimani Province, Iraq
}

\author{
Dilshad 0. Jaff'1, Tariq A. G. Aziz ${ }^{2}$, Natalie R. Smith ${ }^{3}$ \\ ${ }^{1}$ Gillings Global Gateway ${ }^{\mathrm{TM}}$, Gillings School of Global Public Health, University of North Carolina, Chapel Hill, USA \\ ${ }^{2}$ Deptartment of Microbiology, College of Medicine, Sulaimani University, Sulaymaniyah, Iraq \\ ${ }^{3}$ Department of Biostatistics, Gillings School of Global Public Health, University of North Carolina, Chapel Hill, \\ USA \\ Email: jdilshad@email.unc.edu
}

Received 8 December 2015; accepted 25 January 2016; published 28 January 2016

Copyright (C) 2016 by authors and Scientific Research Publishing Inc.

This work is licensed under the Creative Commons Attribution International License (CC BY).

http://creativecommons.org/licenses/by/4.0/

(c) (i) Open Access

\section{Abstract}

Human rotavirus and adenovirus infections are major causes of acute outbreaks and sporadic cases of gastroenteritis, occurring primarily among children less than 5 years of age. Little is known about the epidemiology of rotavirus and enteric adenovirus infections in Sulaimani and Iraq. The aim of this study was to determine the incidence and clinical significance of rotavirus and enteric adenovirus gastroenteritis and also to determine possible risk factors for rotavirus and adenovirus gastroenteritis using new simple rapid screening test (VIKIA ROTA AND ADENO). This is a qualitative test based on the immunochromatography technique. In the study, one hundred children less than 5 years of age with acute gastroenteritis admitted to Sulaimani Paediatric Hospital were studied. Rotavirus was identified in $22 \%$ of the children, adenovirus was identified in $3 \%$ of the children, and mixed rotavirus and adenovirus was identified in $2 \%$ of the children. All positive cases were younger than 2 years of age. The findings show that rotavirus is most commonly detected. However, there were no significant associations between rotavirus and adenovirus and gender, type of feeding, geographical distribution, the source of drinking water, and the past history of admission to hospital.

\section{Keywords}

Rotavirus, Adenovirus, Gastroenteritis, Immunochromatography, Children 


\section{Introduction}

Many different agents including viruses, bacteria, and parasites can cause acute gastroenteritis associated with acute diarrhea. Acute gastroenteritis remains a major public health problem. According to the World Health Organization (WHO), 2 million cases of Diarrhea are seen and 1.9 million children below the age of five die annually because of acute gastroenteritis globally [1]. Viral gastroenteritis is a common cause of morbidity and mortality worldwide. More than 20 different types of viruses have been identified as etiological agents for gastroenteritis [2]. Rotavirus is the most common cause of viral gastroenteritis in infants and young children [3], and it is responsible for approximately $20 \%$ of deaths associated with diarrheain children under 5 years of age worldwide [4]. Each year rotavirus causes an estimated 111 million episodes of diarrhea requiring home care, two million hospitalizations, and 400,000 deaths in children under 5 years mainly in developing countries in Asia, Africa, and Latin America accounting $82 \%$ of the total disease burden [5]. Recent studies report enteric adenovirus as the second most frequent acute gastroenteritis factor after rotavirus in children under the age of five [6] [7]. Rotavirus and adenovirus cause similar manifestations, but gastroenteritis due to adenovirus is accompanied by less vomiting and dehydration than that due to rotavirus [8]. Previous studies on viral etiology of acute gastroenteritis in Iraq reported rotavirus and enteric adenovirus were most frequently associated with acute gastroenteritis in children in Iraq [9]-[12]. An early diagnosis of rotavirus infection for the physician could affect patients' care management in that the unnecessary administration of antibiotics could be avoided, and unnecessary hospitalization with the concomitant risk of nosocomial spread of rotavirus could be prevented. Laboratories attached to small hospitals and outlying clinics catering to the needs of rural communities would also benefit from a rapid and easy-to-perform test for the detection of rotavirus [13]. Continuous surveillance of diarrhea caused by rotavirus and adenovirus in infants and young children would play an important role in diagnosis, treatment, prevention and prophylaxis in order to improve the health of children in the Iraqi Kurdistan, and therefore this study was done to investigate the epidemiology of rotavirus and adenovirus gastroenteritis infections among children less than 5 years of age in Sulaimani province, and to investigate the effect of breast feeding, geographical distribution and the source of drinking water on the incidence of viral gastroenteritis due to rotavirus and adenovirus in Sulaimani province.

\section{Materials and Methods}

\subsection{Study Population}

Samples collected randomly from one hundred admitted cases who attended Sulaimani Pediatric Hospital (a tertiary care hospital) during May and June 2007. Children under 5 who presented to the hospital with acute watery diarrhea and required hospitalization were enrolled. Verbal consent was obtained from the child's parent or guardian before inclusion in the study. The child's parent or guardian was interviewed concerning date of onset of diarrhea, associated symptoms like vomiting and fever, type of feeding, source of drinking water and past history of admission to hospital. Information from medical records was collected on the duration and frequency of diarrhea, duration and frequency of vomiting, degree of fever, gender, age, geographical location and treatment.

\subsection{Materials}

VIKIA $^{\circledR}$ ROTA AND ADENO (Biomerieux France) is a qualitative test based on the immunochromatography technique (ICT); it is a rapid test depends on the association of monoclonal antibodies specific to rotavirus and adenoviruses respectively. This test uses immunological reactions performed on a test strip by migration.

The test consists of:

1) A plastic device containing:

a) A chromatographic membranes to which are fixed:

- In the test region, an anti-rotavirus monoclonal antibody (test region $\mathrm{R}$ ) and an anti-adenovirus monoclonal antibody (test region A).

- In the control region, an anti-mouse IgG polyclonal antibody (Control region C) as shown in Figure 1.

b) A test strip impregnated with a conjugate consisting of a mixture of monoclonal anti-rotavirus antibody coupled to blue dyed polystyrene micro spheres and monoclonal anti-adenovirus antibody coupled to red dyed polystyrene micro spheres. 


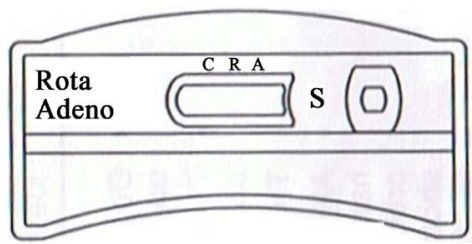

\section{Figure 1. A plastic VIKIA ROTA AND ADENO device.}

2) Vial of faecal specimen dilution buffer which is ready to use, phosphate buffer ( $\mathrm{pH} 7.2)+0.9 \mathrm{~g} / \mathrm{l}$ sodium azide.

3) Waterproof recipient for specimen collection.

4) Timer.

\subsection{Specimen Collection}

One hundred stool specimens ( $1-2 \mathrm{ml}$ or $1-2 \mathrm{~g}$ ) were collected at the onset of the symptoms from hospitalized children aged between 2 months - 5 years at paediatric hospital in Sulaimani and data collection with clinical history was recorded for each child in a special form made for this reason in this study. The stool samples were collected in clean, dry, waterproof recipients containing no detergents, preservatives or transport media, and transferred to the laboratory within 6 hours following collection and stored at $2^{\circ} \mathrm{C}-8^{\circ} \mathrm{C}$. The test was performed within 72 hours following collection. When the specimen was not tested within 72 hours, it was frozen at $-25^{\circ} \mathrm{C}$ or $-6^{\circ} \mathrm{C}$ and to be tested later.

\subsection{Specimen Preparation}

The stool was brought to room temperature $\left(15^{\circ} \mathrm{C}-30^{\circ} \mathrm{C}\right)$ before performing the test, the cap on the vial was unscrewed and the applicator stick required to collect the specimen removed. Approximately $50 \mathrm{mg}$ of stools was collected (equivalent to $1 / 4$ of a pea) using the applicator stick in the vial. The sample inserted into the vial containing the dilution buffer. In case of liquid stools, the specimen collected by using the specimen dropper and 2 drops (approximately 50 micro liters) dispensed into the vial containing the diluted buffer, then the cap was screwed onto the vial and shook vigorously to homogenize the stool suspension.

\subsection{The Procedure}

The test device removed from the sealed pouch and used as soon as possible, then the tip of the vial was broken and turned upside down and it was hold vertically, 2 drops of diluted sample (approximately 80 micro litres) transferred to the sample well(s) of the test device \& then the timer started, trapping air bubbles avoided in the sample well(s) as shown in Figure 2 and Figure 3.

\section{Statistical Analysis}

SAS version 9.4 was used for data analyses. Complete data was only available for children with a positive viral diagnosis of any kind. Statistical analyses were therefore performed only on those children with positive diagnoses. To determine whether there were any significant associations between viral type and various demographic and environmental factors, Fisher's exact test was used (because of small sample size). Finally, because full data was only available for children with viral diagnosis, conclusions from the statistical analyses are interpretable as associations given a positive viral diagnosis.

\section{Results}

\subsection{Prevalence of Rotavirus and Adenovirus Infection}

Faecal samples from 100 hospitalized children less than 5 years at Sulaimani Paediatric Hospital in May and June, 2007, with acute diarrhea and vomiting due to gastroenteritis were tested for rotavirus and enteric adenoviruses infection by VIKIA ${ }^{\circledR}$ ROTA AND ADENO test (Biomerieux, France). Rotavirus was detected in 22 specimens (22\%), adenovirus was detected in 3 specimens (3\%), and mixed rotavirus and adenovirus was detected in 2 specimens (2\%). 


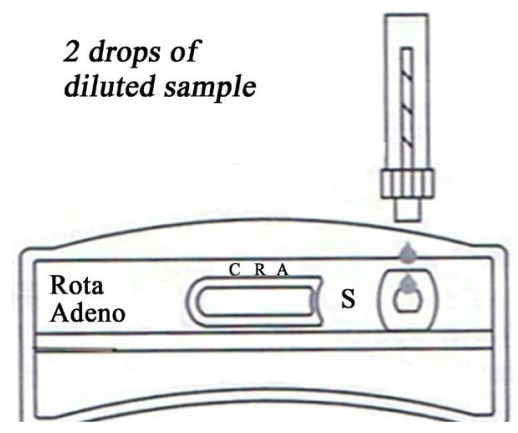

Figure 2. Two drops of the diluted sample transferred to the sample well of the device.
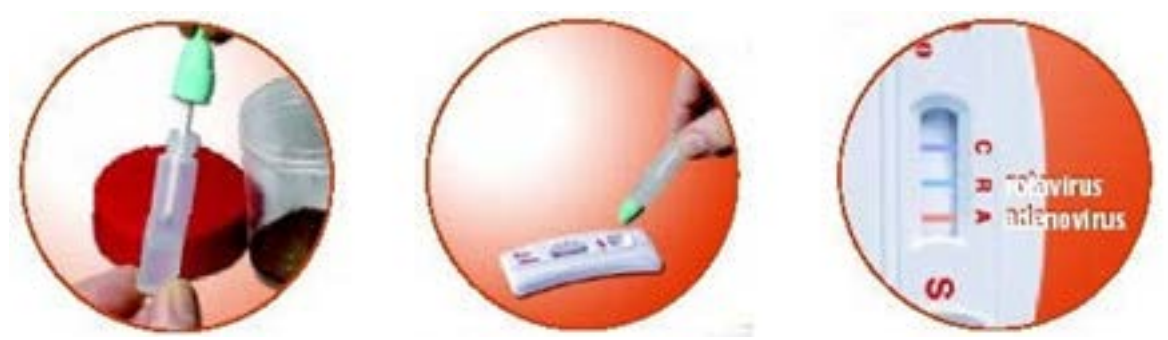

Figure 3. The steps of performing the test with the lines of the results. (Reference: www.biomerieux-diagnostics.com). The control line (C) will appear and possibly lines (R and/ or A) (Figure 3). The results were read in 10 minutes after having dispensed the sample.

\subsection{Prevalence of Rotavirus and Adenovirus Infection in Relation to Gender}

Proportion of rotavirus infection according to the sex of patients were $13 \%$ in males and $9 \%$ in females, proportion of enteric adenoviruses infection were $2 \%$ in males and $1 \%$ in females, and proportion of mixed rotavirus \& enteric adenoviruses infection were $2 \%$ in males and no positive cases were detected in females (Table 1). In children diagnosed with any sort of virus, no significant association between type of virus and gender was observed $(\mathrm{p}=0.7226)$.

\subsection{Prevalence of Rotavirus and Adenovirus Infection According to Patient's Age}

The number of positive cases for rotavirus and adenovirus infections according to the patient's age is shown in Table 2. More positive cases were seen in children aged 1 - 2 years, in comparison to children below one year of age. Of the 27 children diagnosed with gastroenteritis, no significant association between virus type and age was observed $(\mathrm{p}=0.8886)$.

\subsection{Prevalence of Rotavirus and Adenovirus Infection According to the Type of Feeding}

Table 3 shows that among the 22 positive cases of rotavirus infection, 13 were bottle fed, 5 were breast fed and 4 were mixed fed. In case of adenovirus infection out of 3 positive cases 2 were bottle fed and 1 was breast fed, while in case of mixed infection the two positive cases were bottle fed. Infection in relation to the type of feeding showed that $62.90 \%$ were bottle feed, $22.20 \%$ were breast feed, and $14.80 \%$ were mixed fed. No significant association between virus type and type of feeding was observed in children diagnosed with gastroenteritis $(\mathrm{p}=$ 1.000).

\subsection{Prevalence of Rotavirus and Adenovirus Infection According to Geographical Distribution}

Table 4 shows that among Rotavirus infection 19 cases were from urban area and 3 were from rural area, while in adenovirus infection 2 cases were from urban area and 1case only from rural area, the same case was with mixed infection two from urban area. Within children diagnosed with gastroenteritis, no significant association between viral type and geographical region was observed $(\mathrm{p}=0.5832)$. 
Table 1. Count of viral infections by gender in hospitalized children with diagnosed viral infection.

\begin{tabular}{ccccc}
\hline \multirow{2}{*}{ Gender } & \multicolumn{3}{c}{ Virus type } & Total \\
\cline { 2 - 4 } & Rotavirus & Enteric adenovirus & Mixed infection & 17 \\
Male & 13 & 2 & 2 & 10 \\
Female & 9 & 1 & 0 & 2 \\
Total & 22 & 3 & 2 & 27 \\
\hline
\end{tabular}

Table 2. Count of viral infections by age in hospitalized children with diagnosed viral infection.

\begin{tabular}{ccccc}
\hline \multirow{2}{*}{ Age (months) } & \multicolumn{2}{c}{ Virus type } & Total \\
\cline { 2 - 4 } 5 & Rotavirus & Enteric adenovirus & Mixed infection & 1 \\
6 & 1 & 0 & 0 & 1 \\
7 & 1 & 0 & 0 & 2 \\
8 & 2 & 0 & 0 & 3 \\
9 & 2 & 0 & 1 & 2 \\
10 & 1 & 1 & 0 & 2 \\
11 & 2 & 0 & 0 & 1 \\
12 & 1 & 0 & 0 & 9 \\
24 & 7 & 1 & 1 & 6 \\
\hline
\end{tabular}

Table 3. Count of viral infections by type of feeding in hospitalized children with diagnosed viral infection.

\begin{tabular}{ccccc}
\hline & \multicolumn{3}{c}{ Virus type } & Total \\
\cline { 2 - 4 } Feeding & Rotavirus & Enteric adenovirus & Mixed infection & 17 \\
Bottle & 13 & 2 & 2 & 6 \\
Breast & 5 & 1 & 0 & 4 \\
Mixed & 4 & 0 & 0 & 27 \\
Total & 22 & 3 & 2 & 4 \\
\hline
\end{tabular}

Table 4. Count of viral infections among geographic region in hospitalized children with diagnosed viral infection.

\begin{tabular}{ccccc}
\hline \multirow{2}{*}{ Region } & \multicolumn{3}{c}{ Virus type } & Total \\
\cline { 2 - 4 } & Rotavirus & Enteric adenovirus & Mixed infection & 23 \\
Urban & 19 & 2 & 2 & 4 \\
Rural & 3 & 1 & 0 & 2 \\
Total & 22 & 3 & 2 & 27 \\
\hline
\end{tabular}

\subsection{Prevalence of Rotavirus and Adenovirus Infection According to the Source of Drinking Water}

Table 5 shows that among patients with rotavirus infection 14 cases were using tab water and 8 cases uses water from wells. In case of adenovirus 2 cases were using tab water and 1 case was using water from well, while in the mixed infection 1 case was using tab water and the other case was using water from well for drinking. No significant association between the type of virus and drinking water source was observed in children with gastroenteritis $(\mathrm{p}=0.4143)$. 
Table 5. Count of viral infections by source of drinking water in hospitalized children with diagnosed viral infection.

\begin{tabular}{ccccc}
\hline \multirow{2}{*}{ Water source } & \multicolumn{3}{c}{ Virus type } & Total \\
\cline { 2 - 4 } & Rotavirus & Enteric adenovirus & Mixed infection & 17 \\
Tab water & 14 & 2 & 1 & 1 \\
Well water & 8 & 1 & 1 & 10 \\
Total & 22 & 3 & 2 & 1 \\
\hline
\end{tabular}

Table 6. Count of viral infections by hospital admission in hospitalized children with diagnosed viral infection.

\begin{tabular}{cccc}
\hline \multirow{2}{*}{ Hospital admission } & \multicolumn{3}{c}{ Virus type } \\
\cline { 2 - 4 } & Rotavirus & Enteric adenovirus & Mixed infection \\
\hline First time & 9 & 1 & 0 \\
Second time & 13 & 2 & 2 \\
Total & 22 & 3 & 2 \\
\hline
\end{tabular}

\subsection{Prevalence of Rotavirus and Adenovirus Infection According to the Past History of Admission to Hospital}

Table 6 shows that among rotavirus infection 9 cases were first time admitted to hospital and 13 cases were second time admitted to hospital. In adenovirus infection 1 case was first time admitted to hospital and 2 cases were second times admitted to hospital, while in mixed infection both of the 2 cases was admitted for second time to hospital. Within children diagnosed with gastroenteritis, no significant association between viral type and history of hospital admission was observed $(\mathrm{p}=0.7726)$.

\section{Discussion}

Rotavirus infections occur worldwide. Most symptomatic infections are seen in children less than 2 years of age, by the age of 3 years, more than $90 \%$ of children have been infected with most of the major serotypes. There may be evidence of subclinical infection in older children and adults who may be the source of infection for young children in the family or nursery outbreaks. Hospital infection is another important source of infection in hospitalized children for other clinical causes (especially respiratory diseases). It has been reported that the maximum excretion of rotavirus and adenovirus in the stools of patients with gastroenteritis occurs 3 - 5 days and 3 - 13 days respectively after the symptoms have appeared. Clinical interest revived in the middle of 1970's with the discovery of two serotypes (types 40 and 41 ) linked to that previously elusive entity "viral gastroenteritis". This revival of clinical interest has been extended by the discovery in rapid succession of six new serotypes (numbered 42 - 47), most of them in patients with Acquired Immunodeficiency Syndrome (AIDS). Adenoviruses rarely damage their human hosts seriously, but their activities and epidemiology should have important lessons for medicine and investigations are overdue.

In the present study, the incidence of rotavirus and adenovirus gastroenteritis in Sulaimani, Kurdistan region in children less than five years of age were investigated. Our finding shows that rotavirus is most commonly detected and responsible for $22 \%$ of admissions for acute gastroenteritis. This proportion is lower than that observed in Babylon (56\%) [10], Erbil (37\%) [14], Baghdad (23.33\%) [12], Saudi Arabia (40.7\%) [15], and Shiraz in Iran (42\%) [16].

On the other hand, adenovirus is responsible for $3 \%$ of admissions for acute gastroenteritis. Studies in Babylon and Baghdad have reported 20\% and 2.23\% respectively [10] [12]. In neighboring country Iran, adenovirus gastroenteritis reported in $16.2 \%$ of viral diarrheal cases [17]. The great majority of infections with adenoviruses are probably undiagnosed and the full extent of pathogenesis is under-reported. Serotypes 40 and 41 have been isolated from endemic cases of childhood diarrhea and, in number of cases, are second only to rotavirus infection.

Regarding adenovirus infections, estimates of the proportion varies between different laboratories but they contribute up to a third of such cases in which a virus is found. As with other viruses found in diarrheal faeces, such adenoviruses may also be present less frequently in the faeces of apparently normal babies, but there is no doubt of their pathogenic potential for the gut [18]. Mixed rotavirus and adenovirus infections were responsible 
for $2 \%$ of admissions for acute gastroenteritis in this study. In Baghdad, Rotavirus-adenovirus co-infection was reported 1.56\% [12], and in Shiraz in Iran it was reported 4\% [16]. In a study carried out by Roman E, et al., from October 1996 to November 1997 in Spanish children under 4 years old admitted to hospitals with acute gastroenteritis, rotavirus and adenovirus mixed infection were the most common infection with $25.6 \%$ incidence [19]. In this study, the diarrheal stool for rotavirus infected children was semisolid loose whitish to yellowish in color, while it was watery for cases infected with adenovirus and mixed infections. Also in the present study, rotavirus, adenovirus and mixed viruses detection rates were among the children with low socioeconomic status.

Furthermore, we found that the count of viral infections among children who did have tab water at home was higher than among children who did not have tab water, but the association was not statistically significant. This indicates that clean water supplies have not significantly decreased the incidence of rotavirus and adenovirus gastroenteritis. Furthermore, lower counts of rotavirus and adenovirus gastroenteritis were found in children who were exclusively breastfed. Although the association was not significant in our sample, this might be due to the presence of immunological active factors in breast-milk.

In the present study, $78 \%$ of the cases of rotavirus and adenovirus gastroenteritis were in children less than two years of age, which suggests that the younger group was more easily infected by rotavirus and adenovirus than the older group. This might be explained by the fact that older children may have acquired protective immunity as a result of previous exposures to rotavirus which give them immunity to infection with this agent as showed by Jiang B et al. [20] Thus study also showed higher counts of viral infection in males than in females, as seen by other researchers [9] [15].

\section{Conclusion}

In conclusion, rotavirus is a common cause of acute gastroenteritis in children under two years of age in Sulaimani province. The data suggest that interventions should concentrate on children less than 2 years of age, where disease is most common. Although laboratory confirmation of rotavirus would be preferable, the simplicity, high specificity, and speed of VIKIA ${ }^{\circledR}$ ROTA AND ADENO kit make it useful for rapidly screening symptomatic patients. Even in the absence of advanced laboratory techniques, it would be desirable for medical staff to initiate surveillance for rotavirus in patients, in contacts, and in the community.

\section{Acknowledgements}

We thank the management and staff of Sulaimani Pediatric Hospital for their cooperation and support. We thank also the Gillings Global Gateway ${ }^{\mathrm{TM}}$ for paying the publication fee.

\section{References}

[1] Celik, C., Gozel, M.G., Turkay, H., et al. (2015) Rotavirus and Adenovirus Gastroenteritis: Time Series Analysis. Pediatrics International, 57, 590-596. http://dx.doi.org/10.1111/ped.12592

[2] Money, N.N., Maves, R.C., Sebeny, P., et al. (2011) Enteric Disease Surveillance under TEH AFHSC-GEIS: Current Efforts, Landscape Analysis and Vision Forward. BMC Public Health, 11, 572-511. http://dx.doi.org/10.1186/1471-2458-11-S2-S7

[3] Levinson, W. (2004) Medical Microbiology \& Immunology, Examination \& Board Review. 8th Edition, McGraw-Hill Companies, Inc., 281-282, 255-256.

[4] Nguyen, T.V., Van, P.L., Huy, C.L. and Weintraub, A. (2004) Diarrhoea Caused by Rotavirus in Children Less than 5 Years of Age in Hanoi, Vietnam. Journal of Clinical Microbiology, 42, 5745-5750. http://dx.doi.org/10.1128/JCM.42.12.5745-5750.2004

[5] Parashar, U.D., Burton, A., Lanata, C., et al. (2009) Global Mortality Associated with Rotavirus Disease among Children in 2004. Journal of Infectious Diseases, 200, S9-S15. http://dx.doi.org/10.1086/605025

[6] Sire, J.M., Garin, B., Chartier, L., et al. (2013) Community-Acquired Infectious Diarrhoea in Children under 5 Years of Age in Dakar, Senegal. Paediatrics and International Child Health, 33, 139-144. http://dx.doi.org/10.1179/2046905512Y.0000000046

[7] Bonkoungou, I.J., Haukka, K., Österblad, M., et al. (2013) Bacterial and Viral Etiology of Childhood Diarrhea in Ouagadougou, Burkina Faso. BMC Pediatrics, 13, 1-6. http://dx.doi.org/10.1186/1471-2431-13-36

[8] Walker, T.S. (1998) Microbiology. W.B. Saunders Company, 348, 353-356, 404-405.

[9] Ali, G.I., Abdullah, H.I. and Younis, H.M. (2010) Rotavirus Infection in Children Suffering from Gastroenteritis in 
Kirkuk Province. Tikrit Journal of Pure Science, 15, 174-178.

[10] Al-Marzoqi, A.H., Shemmran, A.R. and Al-Nafee', M.K. (2010) Role of Rotavirus and Adenovirus in Acute Infantile Gastroenteritis in Infants Younger than One Year of Age in Babylon Province. Journal of Al-Qadisiyah for Pure Science, 15, 1-7.

[11] Salih, N.E. (2009) Rota Virus Association Diarrhea among Children Less Than 5 Years in Mosul City. Tikrit Journal of Pure Science, 14, 76-80.

[12] Al-Sayidi, R.H., Fadhil, H.Y. and Al-Hamdani, F.G. ((2014) Rapid Diagnosis of Rota-Adenoviruses for Acute Gastroenteritis in Hospitalized Children under 4 Years Old, Baghdad. International Journal of Current Microbiology and Applied Sciences, 3, 453-458.

[13] Schoub, B.D., Greeff, A.S., Lecatsas, G., Prozesky, O.W., et al. (1977) A Microbiological Investigation of Acute Summer Gastroenteritis in Black South African Infants. Journal of Hygiene, 78, 377-385. http://dx.doi.org/10.1017/S0022172400056278

[14] Ahmed, H.M., Coulter, J.B., Nakagomi, O., et al. (2006) Molecular Characterization of Rotavirus Gastroenteritis Strains, Iraqi Kurdistan. Emerging Infectious Diseases, 12, 824-826. http://dx.doi.org/10.3201/eid1205.051422

[15] Khalil, M., Azhar, E. and Kao, M. (2015) Gastroenteritis Attributable to Rotavirus in Hospitalized Saudi Arabian Children in the Period 2007-2008. Clinical Epidemiology, 7, 129-137. http://dx.doi.org/10.2147/CLEP.S69502

[16] Motamedifar, M., Amini, E. and Shirazi, P.T. (2013) Frequency of Rotavirus and Adenovirus Gastroenteritis among Children in Shiraz, Iran. Iranian Red Crescent Medical Journal, 15, 729-733. http://dx.doi.org/10.5812/ircmj.4415

[17] Sharifi-Rad, J., Alfatemi, S.M., Sharifi-Rad, M. and Miri, A. (2015) Frequency of Adenoviruses, Rotaviruses and Noroviruses among Diarrhea Samples Collected from Infants of Zabol, Southeastern Iran. Jundishapur Journal of Microbiology, 8, 1-4.

[18] Peiris, J.S.M. and Madeley, C.R. (2002) Adenoviruses in Medical Microbiology. In: Greenwood, D., Slack, R.C.B. and Peutherer, J.F., Eds., Medical Microbiology, 16th Edition, Churchill Livingstone, New York.

[19] Roman, E., Wilhelmi, I., Colomina, J., et al. (2003) Acute Viral Gastroenteritis: Proportion and Clinical Relevance of Multiple Infections in Spanish Children. Journal of Medical Microbiology, 52, 435-440. http://dx.doi.org/10.1099/jmm.0.05079-0

[20] Jiang, B., Gentsch, J.R. and Glass, R.I. (2002) The Role of Serum Antibodies in the Protection against Rotavirus Disease: An Overview. Clinical Infectious Diseases, 34, 1351-1361. http://dx.doi.org/10.1086/340103 